\title{
Analyzing Relationship between Financing Constraints, Entrepreneurship, and Agricultural Company Using AI-Based Decision Support System
}

\author{
Xiaohu Liu $(\mathbb{D}$, Han Li $\mathbb{D}$, and Hong Li $\mathbb{D}$ \\ Department of Economics and Trade, Xinjiang Agricultural University, Urumqi 830000, Xinjiang, China \\ Correspondence should be addressed to Hong Li; lhcgh@xjau.edu.cn
}

Received 21 October 2021; Revised 13 December 2021; Accepted 14 December 2021; Published 6 January 2022

Academic Editor: Rahman Ali

Copyright (c) 2022 Xiaohu Liu et al. This is an open access article distributed under the Creative Commons Attribution License, which permits unrestricted use, distribution, and reproduction in any medium, provided the original work is properly cited.

\begin{abstract}
Decision support technology has become a key link in modern information strategy. With the deepening of research, introduced expert systems have been introduced into decision support systems. In this way, decision support systems gradually become more uncertain and capable of handling uncertainties. The development direction of decision support system is typically based on qualitative analysis. Intelligent decision support system is a system that combines decision support system with artificial intelligence technology. This study attempts to assess in an innovative way the relationship between financing constraints, entrepreneurship, and agricultural firms. The most recently proposed intelligent decision support system, AI-assisted Intelligent Decision Support System (AIIDSS), is used to predict the impact of entrepreneurship on corporate performance. The paper constructs an entrepreneurship index from five aspects: innovation, competitiveness, human capital accumulation, management capability, and adventurous spirit. The method intends to construct the Kaplan-Zingales (KZ) index to evaluate financing constraints. Through an empirical study, it was found that entrepreneurship can significantly promote the growth of listed agricultural companies. The study can drastically reduce the difficulties involved in financing constraints normally faced by agricultural companies. The impact paths include increasing agricultural company operating cash flow, improving stock liquidity, and increasing debt financing. The research suggests that if listed agricultural companies are to improve financing constraints, entrepreneurs must improve their own competitiveness and management capabilities. This will help in reasonably controlling research and development investment besides the impulse to take risks. As the growth of an enterprise relies on considering the determinants of financing constraints, this research provides an effective investigation technique. Moreover, the findings of the study will help entrepreneurs, particularly agricultural companies, to bear most of the risks and to avail most of the opportunities.
\end{abstract}

\section{Introduction}

Financing difficulty has always been a barrier to the growth of agricultural companies. Previous studies on the financing constraints are mainly conducted from two perspectives: one is the defects of the financial market, whereas the other is about the internal problems of agricultural companies. These studies might be applicable to agricultural companies to a certain extent, but the research objects are rarely agricultural companies [1]. Entrepreneurship is regarded as the key to the development of agricultural companies [2]. It is generally believed that good corporate governance, outstanding entrepreneurs, and a suitable external environment are important factors to the development of a company. Unlike mature companies with a high level of corporate governance, smalland medium-sized companies (SMEs) in the start-up stage rely much on the capabilities of their entrepreneurs [3]. Moreover, compared with SMEs in other industries, agricultural companies are faced with multiple uncertainties of technical barriers, products and markets, and business models, so entrepreneurship is particularly valuable to them [4].

After a thorough review of the existing literature, this study provides the following improvements to their limitations. First, among studies about entrepreneurship or financing constraints, few empirical studies directly focused on agricultural companies [5-10]. This study selects listed agricultural companies as the sample to make up for this deficiency. Moreover, we believe that listed agricultural companies can well represent 
agricultural companies. Second, in terms of research methods, previous studies mainly used a single proxy indicator method or subjective scoring method. The former lacks rationality, and the latter is subject to the researcher's subjective psychological influence of the scoring subject. This paper chooses five objective variables to construct an entrepreneurship index. These five variables are innovation, competitiveness, human capital accumulation, management capabilities, and adventurous spirit. Thirdly, although there were studies on entrepreneurship and financing constraints of small- and medium-sized companies, the literature on their relationship is rare. For instance, the entrepreneurs' study [9] suggested that adequate access to capital is one of the hurdles involved in commencing and maturing a new business. Assessing the impact of financial constraints, Kazmi et al. [11] proved that the constraints not only hinder a firm's operations but also delimit the access to working capital and funds. Bernanke and Gertler suggested that financial constraints reduce investment and growth opportunities in a firm [12]. Leitner [13] claimed that financing constraints considerably obstruct growth of a company. Research works about the impact of financing constraints and international trade have also been conducted. Chaney [14] proposed a model to analyze the relationship between financing constraints and international trade. They suggested that the constraints are important enough to be called the primary determinant of exports.

Though extensive research work has been carried out about entrepreneurship and financing constraints in smalland medium-sized firms, there is a scarcity of research about the relationship between entrepreneurship and financing constraints. The few research works available in the literature are merely about the identification of constraints in agricultural finance. For example, the study conducted by Jessop et al. [15] identified nine constraints containing lack of banking technology, high delivery cost and proximity, and so on. This research work focuses on the impact of entrepreneurship on financing constraints. The study intends to uncover the association of entrepreneurship and financing constraints, particularly in agricultural firms. Moreover, the research aimed to discover the impact of various constraints on the performance of agricultural companies. The Artificial Intelligence-Assisted Intelligent Decision Support System (AIIDSS) [16] is utilized for predicting business processes. By taking the regression values of various variables, prediction is performed about the impact of entrepreneurship on corporate performance. Outcomes of this research study may be used by agricultural companies to enhance their financing constraints. Decision support in financing is of utmost importance to efficiently allocate limited resources [17]. To augment the human capability in making accurate and timely decisions, the findings of the research can be used with domain-specific AI-based decision systems.

\section{Theoretical Analysis and Hypothesis Establishment}

Based on previous research and our investigation, we believe that entrepreneurship has four unique positive effects on agricultural companies. First, it can innovate corporate governance. Many listed companies adopt new corporate governance models, such as variable interest entity system and $\mathrm{AB}$ shares system. Second, it can build a new corporate culture. Many agricultural companies adopt flat management with territorial groups as the unit of management [18], focusing on the cultivation of project team culture. Third, it can optimize corporate development strategies. New technologies and new business models of listed agricultural companies are constantly emerging, and investment strategies need to be continuously optimized. Fourth, it can promote product innovation. Innovation is the foundation for the long-term development of a company, and entrepreneurs are the promoters of product innovation and research and development. Based on the analysis above, the following hypotheses are established.

Hypothesis 1. Entrepreneurship can promote the growth of listed agricultural companies.

Although the possibility of listed agricultural companies through equity financing has increased, they still face strong equity financing constraints. The reasons are as follows. First, there are a large number of listed agricultural companies, and large differences exist in their operating conditions. Therefore, investors have difficulty in making a judgment, and their willingness to invest is not high. Second, the listed agricultural companies have internal problems, which lead to a lower resource allocation efficiency, and so their valuation level is not high. In addition, many listed agricultural companies have low levels of profitability and still face strong credit financing constraints. Their financial system is still incomplete, and risks cannot be assessed; corporate governance is generally imperfect, and a sound corporate governance framework has not been established; some companies who operate with light assets lack collateral for bank loans.

The existence of financing constraints restricts the development of agricultural companies [19], and CEOs of agricultural companies bear the responsibility to acquire financing from outside. Excellent entrepreneurs can alleviate the financing constraints faced by their companies for the following reasons. First, entrepreneurs with entrepreneurship can make full use of their skills to improve the business performance of companies and increase the cash flow of business activities, thereby increasing the endogenous financing of companies. Second, in the private equity market, entrepreneurship is valued by private equity institutions. Venture capital funds mainly invest in start-ups or immature small- and medium-sized companies who do not have mature products or stable markets [20], so the venture capital investors emphasized more on whether the entrepreneurs have excellent qualities, including innovative spirit, competition, consciousness, management ability, and adventurous spirit [21]. Third, in the capital market, entrepreneurs, as corporate spokespersons, are closely evaluated by their behaviors. Outstanding entrepreneurs are corporate images and intangible assets and valued high by investors. Fourth, in the credit market, investors are more likely to believe and invest in companies with a good social reputation and entrepreneurship. Based on the above analysis, the following two hypotheses are proposed. 
Hypothesis 2. Agricultural companies' financing constraints have a negative inhibitory effect on the growth of companies [6]. Entrepreneurship can ease the financing constraints, thereby promoting the growth of agricultural companies.

Hypothesis 3. Entrepreneurship can alleviate financing constraints by increasing business cash flow, attracting private equity funds, improving stock transactions and obtaining more loans in the credit market, and lowering financing costs.

\section{Methodology}

Prior to statistical analysis, samples containing real data were obtained from the well-known agricultural industries of China. Based on the industry classification of the China Securities Regulatory Commission, agricultural processing industry companies listed on the Shanghai and Shenzhen stock exchanges were selected for the study. The companies are among the major agricultural categories and manufacturing industries from 2017 to 2019. Detail about the methodology is presented in the following subsections.

3.1. Sample Selection and Data Sources. After excluding ST companies and samples with serious data missing, the final unbalanced panel data containing 64 company samples are obtained. All sample data are collected and sorted according to the RESSET database and Juchao Information Network.

3.2. Variable Setting and Description. Measuring the various aspects is important for the promotion of entrepreneurship. Without proper measurement of the related variables, it becomes difficult to understand whether entrepreneurship would be flourished or not [22]. For easy computation and systematic analysis, the influencing aspects taken into consideration in the research work were assigned to meaningful variables.

3.2.1. Construction of Entrepreneurship Index. As proper indexing is required in computational analysis, the variable setting was initiated from entrepreneurship indexing. The following variables (features/factors) were considered in the process of indexing the entrepreneurship:

(1) The Selection of Variables to Measure Entrepreneurship. The following key aspects were considered to accurately measure entrepreneurship:

(1) Innovation

Innovation is the primary feature of entrepreneurship [23]. Although invention patents are an important sign of measuring a company's technological innovation, they cannot be used due to a lack of relevant data sources. The company's strong scientific research team and sufficient R\&D investment are key factors that lead to technological innovation and patent acquisition, so this study chooses the positive indicator of $\mathrm{R} \& \mathrm{D}$ investment to measure entrepreneurial innovation.

(2) Competitiveness

This study uses two positive indicators of excess profit and firm size to measure entrepreneurial competitiveness [24].

(3) Human capital accumulation

This study chooses the level of education and the working time as the positive indicators of entrepreneurial human capital accumulation [25].

(4) Management competence

This paper selects two negative indicators of violations and litigation and entrepreneurial equity pledge to measure management competence. First, as a listed company, once it violates the relevant regulations of the China Securities Regulatory Commission or encounters a lawsuit, its corporate image will suffer huge losses, which is an important manifestation of imperfect corporate management [26]. Secondly, most studies hold a negative attitude towards the entrepreneurial pledge of equity and regard it as a tunnel behavior of managers, which may hollow out the company [27].

(5) Adventurous spirit

The adventurous spirit is the embodiment of the company's vitality. This paper selects three indicators of gambling agreement, leverage ratio, and external investment in new fields to measure the company's adventurous spirit. Gambling agreements and external investment in new fields are used as positive indicators, and leverage ratio is used as a negative indicator to measure entrepreneurial adventurous spirit.

3.2.2. Calculation of the Entrepreneurship Index. This study uses objective data to reflect the characteristics of entrepreneurship. On the basis of the index system constructed in Table 1, the index is weighted by the entropy weight method to obtain the entrepreneurship index. The entropy method is an objective weighting method, and its basic concept is to determine the weight according to the size of the index difference. The specific steps are as follows:

The first step is to standardize the data. Suppose there are $k$ given indicators $x_{1}, x_{2}, \ldots, x_{k}$, among which $x_{i}=\left\{x_{1}, x_{2}, \ldots, x_{k}\right\}$. Assuming that the standardized values of the indicators are $y_{1}, y_{2}, y_{k}$, then $y_{i j}=x_{i j}-\min \left(x_{i}\right) / \max \left(x_{i}\right)-\min \left(x_{i}\right)$.

The second step is to calculate the information entropy of each indicator. According to the definition of information entropy in information theory, the information entropy of a set of data is $F_{J}=-\ln (n)^{-1} \sum_{i=1}^{n} p_{i j} \ln p_{i j}$. Among them, $p_{i j}=y_{i j} / \sum_{i=1}^{n} y_{i j} ; \quad$ if $\quad p_{i j}=0$, then define $\lim _{p_{i j} \longrightarrow 0} p_{i j} \ln p_{i j}=0$. 
TABLE 1: The proxy variables of entrepreneurship (epsi) and the weight of each variable.

\begin{tabular}{|c|c|c|c|c|c|c|}
\hline Variable & Variable abbreviation & Meaning & Sign & 2017 weight & 2018 weight & 2019 weight \\
\hline Innovation & $\mathrm{R} \& \mathrm{D}$ & R\&D investment ratio & Positive & 0.101932 & 0.101513 & 0.796162 \\
\hline \multirow{2}{*}{ Competitiveness } & SP & Excess profit margin & Positive & 0.102071 & 0.10187 & 0.029287 \\
\hline & Scale & Company scale & Positive & 0.095464 & 0.098097 & 0.029202 \\
\hline \multirow{2}{*}{$\begin{array}{l}\text { Manager's human capital } \\
\text { Accumulation }\end{array}$} & Time & Employment time & Positive & 0.101935 & 0.101724 & 0.016215 \\
\hline & Degree & Level of education & Positive & 0.101935 & 0.101512 & 0.027409 \\
\hline \multirow{2}{*}{ Management capabilities } & WG & Violation and litigation & Negative & -0.102071 & -0.101866 & -0.026854 \\
\hline & Pledge & Equity pledge & Negative & -0.10207 & -0.101866 & -0.02904 \\
\hline \multirow{3}{*}{ Adventurous spirit } & Bet & Gambling agreement & Positive & 0.095253 & 0.0926 & 0.003847 \\
\hline & LEVEL & Leverage ratio & Negative & -0.102017 & -0.1018 & -0.028112 \\
\hline & Invest & External investment in new field & Positive & 0.095253 & 0.097151 & 0.013871 \\
\hline
\end{tabular}

The third step is to determine the weight of each indicator. According to the calculation formula of information entropy, the information entropy of each index is calculated as $F_{1}, F_{2}, \ldots, F_{K}$. Then, the weight of each indicator through information entropy can be calculated: $W_{i}=\left(1-F_{i} / k-\sum F_{i}\right)(i=1,2, \ldots, k)$.

The fourth step is to calculate the entropy index. Use epsi to represent the entrepreneurship index, which is the sum of the standardized value of each variable and the corresponding weight.

As shown in Table 1, among the 10 proxy variables of entrepreneurship, 3 are negative indicators, namely, "whether there are violations and litigation," "whether the entrepreneur himself pledges equity," and "leverage ratio." From the results, the absolute values of the weights of the indicators in 2017 and 2018 are very similar, ranging from 0.09 to 0.1 , indicating that the sample indicator values are very close in these two years. However, in 2019, the weight of each indicator has changed to a certain extent. The main manifestation is that the weight of the indicator "R\&D investment ratio" suddenly becomes larger, which is mainly caused by the increase of the gap in $\mathrm{R} \& \mathrm{D}$ investment of sample companies.

3.2.3. Construction of Financing Constraint Index. With reference to the method of Kaplan and Zingales [28], this study constructs an index $\mathrm{KZ}$ as a tool to evaluate the financing constraints confronted by listed agricultural companies. The specific methods are as follows: (1) the first step is to calculate the ratio of net cash flow from business operating activities to total assets in the previous year (JC), the ratio of monetary cash to total assets in the previous year (CC), asset-liability ratio (LEVEL), and the ratio of corporate value (excluding monetary funds) to the median value of total assets (TQ) in the previous year. (2) If JC is less than the median value, $\mathrm{kz}_{1}=1$; otherwise, it is 0 . Similarly, if CC is less than the median, $\mathrm{kz}_{2}=1$; otherwise, it is 0 . If LEVEL is greater than the median, $\mathrm{kz}_{3}=1$; otherwise, it is 0 . If TQ is greater than the median, $\mathrm{kz}_{4}=1$; otherwise, it is 0 . Thus, $\mathrm{KZ}=\mathrm{kz}_{1}+\mathrm{kz}_{2}+\mathrm{kz}_{3}+\mathrm{kz}_{4}$ is obtained. The $\mathrm{KZ}$ index here represents the degree of financing constraints faced by the company. The larger the $\mathrm{KZ}$ value is, the stronger the financing constraints are faced by the company. (4) With $\mathrm{KZ}$ as the explained variable and JC, CC, LEVEL, and TQ as the explanatory variable, the weighted least-squares regression is performed.
From the results, in line with the expected operating activities, the cash flow is negatively related to financing constraints, the monetary funds held are negatively related to financing constraints, the asset-liability ratio is positively related to financing constraints, and more investment opportunities are positively related to financing constraints. From the perspective of the impact coefficient of each indicator, it is consistent with the results of Liu et al. [19]. The degree of impact from high to low is CC $(12.07 \%)>$ TQ $(9.18 \%)>$ JC $(9.73 \%)>$ LEVEL $(3.38 \%)$.

3.2.4. Other Variables. Besides the stated variables, some related factors have also been analyzed, details of which are given as follows:

(1) Difficulty of Equity Financing. This paper uses the annual average stock exchange rate (stock) as a proxy variable for the difficulty of equity financing. The reason is that the low stock exchange rate of listed agricultural companies is an important manifestation of equity financing difficulties.

(2) The Difficulty of Debt Financing. This paper uses the scale of interest-bearing debt (logarithm) (debt1) and the average interest rate of interest-bearing debt (debt2) to measure the degree of ease for companies to obtain financing in the credit market.

(3) Private Equity Investment (PE). In this paper, whether to obtain private equity investment to assess the difficulty of financing in the private equity market, this is a dummy variable with a yes value of " 1 " and no value of "0."

(4) Corporate Performance. This paper uses an operating income growth rate (Grow) to measure corporate performance.

3.2.5. Control Variables. There is a total of 6 control variables, including equity concentration (SF), liquidity ratio (LR), total asset growth rate (ZZ), inventory growth rate (CCO), industry (INDUS), and year (YEAR).

3.3. Model Setting. To test the hypothesis, this paper establishes the following model and simultaneously uses (least-squares method) OLS and (weighted least-squares 
method) EGLS method for multiple linear regression of panel data. Equations (1) to (3) are established to test Hypothesis 1 , in which equation (1) tests the correlation between entrepreneurship and corporate performance, equation (2) tests the correlation between various aspects of entrepreneurship and corporate performance, and equation (3) adds the cross term of the substitution variable of entrepreneur's human capital accumulation and R\&D investment to test whether the accumulation of entrepreneur's human capital can increase the contribution of R\&D investment to corporate performance. Equation (4) tests Hypothesis 2 by introducing the intersection of entrepreneurship and financing constraints. In addition, in order to further explore the influence of entrepreneurship on financing constraints and the mechanism, this paper establishes regression equation (5) to test Hypothesis 3. Among them, equation (5) examines the direct influence of entrepreneurship on financing constraints, equation (5) examines whether entrepreneurship can help improve corporate cash flow, and equation (5) examines the influence of entrepreneurship on private equity investment. To test the influence of entrepreneurship on equity financing, equation
TABLE 2: Statistical description of the main variables.

\begin{tabular}{lccccc}
\hline Variable & $\begin{array}{c}\text { Observed } \\
\text { value }\end{array}$ & Mean & Median & Maximum & Minimum \\
\hline Grow & 7739 & $71.39 \%$ & $28.20 \%$ & $1295.27 \%$ & $-65.48 \%$ \\
R\&D & 6334 & $14.03 \%$ & $9.89 \%$ & $477.33 \%$ & 0 \\
SP & 8672 & $-32.13 \%$ & $7.02 \%$ & $437.86 \%$ & $-136.28 \%$ \\
Scale & 6342 & 7.621388 & 7.62204 & 9.870861 & 4.522968 \\
Time & 6034 & 6.773119 & 5 & 47 & 0 \\
Degree & 5488 & 1.181305 & 1 & 4 & 0 \\
WG & 8783 & 0.024593 & 0 & 1 & 0 \\
Pledge & 8784 & 0.025615 & 0 & 1 & 0 \\
LEVEL & 8677 & $40.74 \%$ & $36.24 \%$ & $135.20 \%$ & 0 \\
Invest & 8784 & 0.021061 & 0 & 1 & 0 \\
Bet & 8784 & 0.002846 & 0 & 1 & 0 \\
epsi & 8784 & 6.279862 & 7.205743 & 123.8787 & -4162.6 \\
KZ & 7965 & 1.466541 & 2 & 3 & 0 \\
\hline
\end{tabular}

(5) tests the influence of entrepreneurship on the scale of corporate debt, and equation (5) tests the influence of entrepreneurship on the cost of debt.

$$
\begin{aligned}
& \mathrm{Grow}_{i t}=\alpha+\beta \mathrm{epsi}_{i t}+\text { Control Variables }_{i t}+\varepsilon_{i t} \text {, } \\
& \text { Grow }_{i t}=\alpha+\beta_{1} \mathrm{R} \& D_{i t}+\beta_{2} \text { S.P }_{i t}+\beta_{3} \text { Scale }_{i t}+\beta_{4} \text { Time }_{i t}+\beta_{5} \text { Degree }_{i t} \\
& +\beta_{6} W G_{i t}+\beta_{7} \text { Pledge }_{i t}+\beta_{8} \text { Bet }_{i t}+\beta_{9} \text { Invest }_{i t}+\beta_{10} \text { Level }_{i t} \\
& + \text { Control Variables }{ }_{i t}+\varepsilon_{i t} \text {, } \\
& \mathrm{Grow}_{i t}=\alpha+\beta_{1} \mathrm{R} \& \mathrm{D}_{i t}+\beta_{2} \mathrm{R} \& \mathrm{D}_{i t} * \mathrm{Time}_{i t}+\beta_{3} \mathrm{R} \& \mathrm{D}_{i t} * \\
& \text { Degree }_{i t}+\text { Control Variables }_{i t}+\varepsilon_{i t} \text {, } \\
& \mathrm{Grow}_{i t}=\alpha+\beta_{1} \mathrm{KZ}_{i t}+\beta_{2} \mathrm{epsi}_{i t} * \mathrm{KZ}_{i t}+\text { Control Variables }{ }_{i t}+\varepsilon_{i t} \text {, } \\
& \frac{\mathrm{KZ}_{i t}}{J C_{i t} / P E_{i t} / \text { stock }_{i t} / \text { debt }_{i t} / \text { debt } 2_{i t}}=\alpha \\
& + \text { epsi }_{i t}+\text { Control Variables }_{i t}+\varepsilon_{i t} \text {. }
\end{aligned}
$$

\section{Empirical Analysis}

Empirical analysis is used to discover precise and provable evidence. In the process, a systematic method is followed to avoid personal bias and to reach a valid conclusion. The following are the steps followed in the analysis of the research work.

4.1. Descriptive Statistics of Variables. As shown in Table 2, numerical figures obtained as the deviation of the mean, the median, and the gap between the maximum and minimum values reveal that the listed agricultural companies differ greatly in corporate performance, $\mathrm{R} \& \mathrm{D}$ investment, and excess profit margins.
4.2. Analysis of Hypothesis 1 Test Results. The regression results of equations (1) to (3) can be found in Table 3. This paper uses both OLS and EGLS methods for verification. The results show that entrepreneurship and corporate performance are significantly positively correlated, thus verifying Hypothesis 1. To be specific, the proxy variable of entrepreneurial innovation spirit R\&D investment is significantly positively correlated with corporate performance, and the proxy variable of entrepreneurial competitiveness is significantly positively correlated with excess profit rate and corporate scale. In terms of entrepreneurial human capital accumulation, the entrepreneurs' education background is positively correlated with corporate performance, but the entrepreneurs' working years are negatively correlated with corporate performance. The result of equation (3) provides 
TABLE 3: Regression results of the impact of entrepreneurship on corporate performance.

\begin{tabular}{|c|c|c|c|c|c|c|}
\hline \multirow{2}{*}{ Variable } & \multicolumn{2}{|c|}{ Equation (1) } & \multicolumn{2}{|c|}{ Equation (2) } & \multicolumn{2}{|c|}{ Equation (3) } \\
\hline & OLS & EGLS & OLS & EGLS & OLS & EGLS \\
\hline epsi & $\begin{array}{l}0.0199^{*} \\
-0.1178\end{array}$ & $\begin{array}{c}0.0312^{* * *} \\
-3.5136\end{array}$ & - & - & - & - \\
\hline $\mathrm{R} \& \mathrm{D}$ & - & - & $\begin{array}{l}0.2925^{*} \\
-1.8015\end{array}$ & $\begin{array}{l}0.2941^{* * *} \\
-18.3446\end{array}$ & $\begin{array}{c}0.1166 \\
-0.4624\end{array}$ & $\begin{array}{c}0.0763^{* * *} \\
-4.2461\end{array}$ \\
\hline SP & - & - & $\begin{array}{c}0.0287 \\
-1.3764\end{array}$ & $\begin{array}{l}0.0285^{* * *} \\
-57.4436\end{array}$ & - & - \\
\hline Scale & - & - & $\begin{array}{c}10.005^{* * *} \\
-2.5804\end{array}$ & $\begin{array}{l}9.9810^{* * *} \\
-32.4053\end{array}$ & - & - \\
\hline Time & - & - & $\begin{array}{l}-0.1141 \\
(-0.3963)\end{array}$ & $\begin{array}{l}-0.2402^{* * *} \\
(-32.4053)\end{array}$ & - & - \\
\hline Time* $^{*} \& D$ & - & - & - & - & $\begin{array}{l}-0.00081 \\
(-0.1616)\end{array}$ & $\begin{array}{c}-0.0058^{* * *} \\
(-0.5676)\end{array}$ \\
\hline Degree & - & - & $\begin{array}{c}2.2765 \\
-1.0783\end{array}$ & $\begin{array}{c}2.0517^{* * *} \\
-12.14\end{array}$ & - & - \\
\hline Degree $^{*} \mathrm{R} \& \mathrm{D}$ & - & - & - & - & $\begin{array}{l}0.2208^{*} \\
-1.7821\end{array}$ & $\begin{array}{l}0.2226^{* * *} \\
-50.0869\end{array}$ \\
\hline WG & - & - & $\begin{array}{l}-4.7016 \\
(-0.5670)\end{array}$ & $\begin{array}{c}-6.5149^{* * *} \\
(-5.3595)\end{array}$ & - & - \\
\hline Pledge & - & - & $\begin{array}{l}-1.0319 \\
(-0.1426)\end{array}$ & $\begin{array}{l}-2.0139^{*} \\
(-2.6590)\end{array}$ & - & - \\
\hline LEVEL & - & - & $\begin{array}{c}-0.3018 \\
(-2.6101) \\
10.8131\end{array}$ & $\begin{array}{c}-0.2907^{* * *} \\
(-33.4821) \\
10.5206^{* * *}\end{array}$ & - & - \\
\hline Invest & - & - & -1.4748 & -9.678 & - & - \\
\hline Bet & - & - & $\begin{array}{c}143.1606^{* * *} \\
-4.6694\end{array}$ & $\begin{array}{c}147.2056^{* * *} \\
-42.02177\end{array}$ & - & - \\
\hline SF & $\begin{array}{c}-0.3179^{* * *} \\
(-3.3050)\end{array}$ & $\begin{array}{l}-0.3058^{* * *} \\
(-39.1225)\end{array}$ & $\begin{array}{c}-0.4163^{* * *} \\
(-4.7757)\end{array}$ & $\begin{array}{l}-0.4228^{* * *} \\
(-225.0855)\end{array}$ & $\begin{array}{c}-0.3793^{* * *} \\
(-4.2674)\end{array}$ & $\begin{array}{l}-0.3988^{* * *} \\
(-106.079)\end{array}$ \\
\hline LR & $\begin{array}{c}0.2469 \\
-0.5071\end{array}$ & $\begin{array}{c}0.3097^{* * *} \\
-9.8134\end{array}$ & $\begin{array}{c}0.9627^{* * *} \\
-2.8368\end{array}$ & $\begin{array}{l}0.9204^{* * *} \\
-59.6912\end{array}$ & $\begin{array}{c}1.0884^{* * *} \\
-2.8246\end{array}$ & $\begin{array}{l}1.0710^{* * *} \\
-24.7097\end{array}$ \\
\hline $\mathrm{ZZ}$ & $\begin{array}{c}50.0220^{* * *} \\
-16.6414\end{array}$ & $\begin{array}{l}50.1458^{* * *} \\
-201.8785\end{array}$ & $\begin{array}{c}46.7507^{* * *} \\
-17.9769\end{array}$ & $\begin{array}{l}46.6339^{* * *} \\
-360.6464\end{array}$ & $\begin{array}{c}52.9724^{* * *} \\
-18.4093\end{array}$ & $\begin{array}{l}52.9557^{* * *} \\
-311.0314\end{array}$ \\
\hline $\mathrm{CCO}$ & $\begin{array}{l}-0.0039 \\
(-0.5964)\end{array}$ & $\begin{array}{c}-0.003768^{* * *} \\
(-0.2696)\end{array}$ & $\begin{array}{c}0.0078 \\
-1.2722\end{array}$ & $\begin{array}{l}0.0079^{* * *} \\
-69.7907\end{array}$ & $\begin{array}{l}-0.0014 \\
(-0.2177)\end{array}$ & $\begin{array}{l}-0.0013^{* * *} \\
(-12.2405)\end{array}$ \\
\hline YEAR & Control & Control & Control & Control & Control & Control \\
\hline INDUS & Control & Control & Control & Control & Control & Control \\
\hline Adjusted $R$-squared & 0.12 & 0.9933 & 0.0906 & 0.9939 & 0.1165 & 0.9884 \\
\hline$N$ & 2678 & 2678 & 3722 & 3722 & 2898 & 2898 \\
\hline
\end{tabular}

${ }^{* * *}$ At level 0.005 (double tails), the correlation was significant. ${ }^{* *}$ At level 0.01 (double tails), the correlation was significant. ${ }^{*}$ At level 0.05 (double tails), the correlation was significant.

an explanation for this. From the result of equation (3), the coefficient of the cross term of the education background and $\mathrm{R} \& \mathrm{D}$ investment is positive, while the correlation coefficient of the cross term of working years and R\&D investment is negative, indicating that young and highly educated entrepreneurs can significantly improve R\&D efficiency. Thirdly, entrepreneurs' management capabilities are significantly positively correlated with corporate performance, and the two negative proxy variables of entrepreneurs' management ability, violation and litigation, and equity pledge are all significantly negatively correlated with company performance. Finally, entrepreneurial risk-taking behavior is significantly positively correlated with corporate performance. Positive proxy variables (external investment in new areas and signing of gambling agreements) are significantly positively correlated with corporate performance, negative proxy variable (asset-liability ratio) is negatively correlated with corporate performance, indicating a moderate increase in corporate investment, and equity financing risks and maintaining a moderate debt scale have a positive influence on corporate performance.

4.3. Analysis of Hypothesis 2 Test Results. Table 4 shows the regression results of equation (4). From the results, the proxy variable $\mathrm{KZ}$ of financing constraints is significantly negatively correlated with the performance of agricultural companies, indicating that financing constraints have significantly inhibited the growth of agricultural companies. The correlation coefficient between the cross item of entrepreneurship index and financing constraints and corporate performance is positive and passes the $1 \%$ significance test, indicating that entrepreneurship can alleviate financing constraints and promote the growth of agricultural companies. Therefore, Hypothesis 2 is verified. 
TABLE 4: Regression results of the impact of financing constraints on corporate growth after considering entrepreneurship.

\begin{tabular}{|c|c|c|}
\hline \multirow{2}{*}{ Variable } & \multicolumn{2}{|c|}{ Equation (4) } \\
\hline & OLS & EGLS \\
\hline \multirow{2}{*}{$\mathrm{KZ}$} & $-8.7952^{* * *}$ & $-8.0498^{* * *}$ \\
\hline & $(-3.5539)$ & $(-37.0122)$ \\
\hline \multirow{2}{*}{ epsi*kz } & $0.3234^{* * *}$ & $0.1113^{* * *}$ \\
\hline & -2.9436 & -30.0838 \\
\hline \multirow{2}{*}{ SF } & $-0.4055^{* * *}$ & $-0.4172^{* * *}$ \\
\hline & $(-4.7239)$ & $(-67.9959)$ \\
\hline \multirow{2}{*}{ LR } & 0.3783 & $0.3782^{* * *}$ \\
\hline & -1.0496 & -5.6119 \\
\hline \multirow{2}{*}{$\mathrm{ZZ}$} & $44.3181^{* * *}$ & $47.5765^{* * *}$ \\
\hline & -16.7032 & -157.2924 \\
\hline \multirow{2}{*}{$\mathrm{CCO}$} & $0.0062^{* *}$ & $0.0067^{* * *}$ \\
\hline & -1.017 & -11.1685 \\
\hline YEAR & Control & Control \\
\hline INDUS & Control & Control \\
\hline Adjusted $R$-squared & 0.99356 & 0.9642 \\
\hline$N$ & 3719 & 3719 \\
\hline
\end{tabular}

TABLE 5: Regression results of the impact of entrepreneurship on financing constraints (EGLS/binary PROBIT).

\begin{tabular}{lcccccc}
\hline Variable & $\begin{array}{c}\text { Equation (5)- } \\
\text { dependent } \\
\text { variable: KZ }\end{array}$ & $\begin{array}{c}\text { Equation (5)- } \\
\text { dependent } \\
\text { variable: JC }\end{array}$ & $\begin{array}{c}\text { Equation (5)- } \\
\text { dependent variable: } \\
\text { PE (PROBIT) }\end{array}$ & $\begin{array}{c}\text { Equation (5)- } \\
\text { dependent } \\
\text { variable: stock }\end{array}$ & $\begin{array}{c}\text { Equation (5)- } \\
\text { dependent } \\
\text { variable: debt1 }\end{array}$ & $\begin{array}{c}\text { Equation (5)- } \\
\text { dependent variable: } \\
\text { debt2 }\end{array}$ \\
\hline epsi & $-0.00316^{* * *}$ & $0.002818^{* * *}$ & -0.01207 & $0.028217^{* * *}$ & $0.002148^{* * *}$ & $1.22 E+11^{* * *}$ \\
& $(-10.2999)$ & -91.41663 & $(-2.75192)$ & -2.378193 & 4.861806 & -3.586374 \\
Constant & $-0.677813^{* * *}$ & $-0.614375^{* * *}$ & $-6.656924^{* * *}$ & $49.59167^{* * *}$ & $54.83734^{* * *}$ & $-2.92 E+16^{* * *}$ \\
& $(-14.55036)$ & $(-73.15327)$ & $(-7.807875)$ & -132.763 & 3.550712 & $(-19.21336)$ \\
Scale & $0.33504^{* * *}$ & $0.05051^{* * *}$ & $0.705291^{* * *}$ & $-5.4205^{* * *}$ & $0.285273^{* * *}$ & $-3.11 E+13^{* * *}$ \\
& -59.22702 & -102.7388 & -7.459384 & $(-135.324)$ & 47.68814 & $(-20.051)$ \\
SF & $-0.00014^{* *}$ & $0.001463^{* * *}$ & $-0.01302^{* * *}$ & $0.068216^{* * *}$ & $0.000381^{* * *}$ & $-2.66 E+11^{* * *}$ \\
& $(-1.91726)$ & -74.33611 & $(-4.7462)$ & -71.28882 & 3.638333 & $(-21.45089)$ \\
LR & $-0.05209^{* * *}$ & $-0.00176^{* * *}$ & $0.031704^{* * *}$ & $-0.05562^{* * *}$ & $-0.00792^{* * *}$ & $-2.75 E+12^{* * *}$ \\
& $(-166.097)$ & $(-21.6377)$ & -4.204081 & $(-13.8188)$ & -9.18876 & $(-20.07745)$ \\
ZZ & $-0.01451^{* * *}$ & $0.022523^{* * *}$ & -0.11097 & $-0.42002^{* * *}$ & $0.05537^{* * *}$ & $-2.56 E+13^{* * *}$ \\
& $(-6.5252)$ & -37.63026 & $(-1.3147)$ & $(-18.3887)$ & 7.978613 & $(-18.08465)$ \\
CCO & $-0.0002^{* * *}$ & $3.81 E-05^{* * *}$ & -0.000005 & $3.49 E+00$ & $-0.00022^{* * *}$ & $-5.40 E+09^{* * *}$ \\
YEAR & $(-19.5065)$ & -5.932283 & $(-0.3118)$ & -0.559766 & -6.23415 & $(-12.3183)$ \\
INDUS & Control & Control & Control & Control & Control & Control \\
Adjusted $R-$ & Control & Control & Control & Control & Control & Control \\
squared & 0.99701 & 0.8504 & 0.15324 & 0.99 & 0.704533 & 0.261459 \\
$N$ & 3299 & 3490 & 3723 & 1600 & 1899 & 1993 \\
\hline
\end{tabular}

${ }^{* * *}$ At level 0.005 (double tails), the correlation was significant. ${ }^{* *}$ At level 0.01 (double tails), the correlation was significant. ${ }^{*}$ At level 0.05 (double tails), the correlation was significant.

4.4. Analysis of Hypothesis 3 Test Results. Table 5 lists the regression results of equation (5). The results show that entrepreneurship is significantly negatively correlated with financing constraints, indicating that entrepreneurs with entrepreneurship can significantly reduce the financing constraints of companies. In terms of the path of influence, the entrepreneurship is significantly positively correlated with the cash generated by business activities, indicating that the entrepreneurship improves the operating conditions of the company while increasing the endogenous financing of the company. Also, entrepreneurship is significantly positively correlated with the ease of equity financing, indicating that entrepreneurship can make it easier for companies to obtain equity financing in the capital market. Third, entrepreneurship is significantly positively correlated with the scale of corporate interest-paying debt, indicating that entrepreneurship can make it easier for companies to obtain debt financing in the credit market. The above conclusion is consistent with the hypothesis.

However, two aspects are inconsistent with the hypothesis. First, entrepreneurship is positively correlated with debt financing costs, indicating that entrepreneurship cannot reduce the credit financing costs of companies while increasing the credit financing of companies. Second, there 
is no significant correlation between entrepreneurship and whether to introduce private equity investment. This may be because private equity investment is mainly introduced before the listing of the company or the start-up period of the company.

4.5. Robustness Test and Further Analysis. A robustness test was conducted to further verify the results. First, referring to previous studies, we use a single variable excess profit rate as a substitute variable for entrepreneurship, and the results show that the excess profit margin is significantly negatively correlated with financing constraints and significantly positively correlated with cash flow from operating activities and ease of equity financing and has no significant correlation with private equity financing, which is consistent with the previous results. However, contrary to the previous results, the excess profit rate is significantly negatively correlated with the scale and cost of debt financing, indicating that the increase in corporate excess profits also reduces the scale and cost of debt financing. Second, we use univariate dividend payment rate and interest guarantee multiple as substitute variables for the financing constraint index $\mathrm{KZ}$, and results show that entrepreneurship can significantly reduce financing constraints.

A further test is conducted to explore the relationship between the five representative elements of entrepreneurship and financing constraints. The results show that competitiveness, management capabilities, and human capital accumulation represented by academic education level have significantly reduced the financing constraints faced by companies; the entrepreneurs' spirit of innovation increases the financing constraints because R\&D investment requires a large amount of capital investment; the entrepreneurship of adventure increases the financing constraints faced by companies, whether it is a risky investment or risky financing. Therefore, in order to alleviate financing constraints, companies should appropriately control R\&D investment while restraining the urge to take risks.

\section{Conclusion}

From an empirical study, it can be found that entrepreneurship can significantly promote the growth of agricultural companies. The accumulation of human capital represented by entrepreneurs' academic education can help improve the efficiency of company research and development. Entrepreneurship can significantly alleviate the inhibitory effect of financing constraints on company development and use this to promote company growth. Entrepreneurship has positive impacts on the reduction of corporate financing constraints. Its influence mechanism includes increasing corporate operating cash flow, improving the liquidity of corporate stocks, and increasing the scale of debt financing. However, the increase in the scale of debt brings an increase in the cost of debt. From further analysis, we found that, within the five representative elements of entrepreneurship, competitiveness, management capabilities, and human capital accumulation represented by academic education significantly reduced the financing constraints faced by companies; innovation spirit increased the financing constraints faced by companies; adventure spirit increased the financing constraints faced by agricultural companies.

\section{Data Availability}

The datasets used and/or analyzed during the current study are available from the corresponding author upon reasonable request.

\section{Conflicts of Interest}

The authors declare no conflicts of interest.

\section{References}

[1] L. Ling and L. Wang, "Financial development and private enterprise financing constraints," Management Journal, vol. 30, no. 01, pp. 52-62, 2017.

[2] X. Liu and H. Zhang, "Innovative spirit, adventurous spirit and corporate growth: an empirical test of the impact of entrepreneurship based on listed company data," China Economic Report, no. 03, pp. 89-105, 2020.

[3] L.-Y. Wu, "Entrepreneurial resources, dynamic capabilities and start-up performance of Taiwan's high-tech firms," Journal of Business Research, vol. 60, no. 5, pp. 549-555, 2007.

[4] O. Sivertsson and J. Tell, "Barriers to business model innovation in Swedish agriculture," Sustainability, vol. 7, no. 2, pp. 1957-1969, 2015.

[5] S. Fazzari, R. G. Hubbard, and B. C. Petersen, Financing Constraints and Corporate Investment (No. W2387), National Bureau of Economic Research, Brookings INST, Washington, DC, USA, 1987.

[6] L. Laeven, "Does financial liberalization reduce financing constraints?" Financial Management, vol. 32, no. 1, pp. 5-34, 2003.

[7] S. N. Kaplan and L. Zingales, "Investment-cash flow sensitivities are not valid measures of financing constraints," Quarterly Journal of Economics, vol. 115, no. 2, pp. 707-712, 2000.

[8] J. R. Brown, G. Martinsson, and B. C. Petersen, "Do financing constraints matter for R\&D?" European Economic Review, vol. 56, no. 8, pp. 1512-1529, 2012.

[9] W. Kerr and R. Nanda, Financing Constraints and Entrepreneurship (No. W15498), Harvard Business School, Boston, MA, USA, 2009.

[10] I. Love, "Financial development and financing constraints: international evidence from the structural investment model," Review of Financial Studies, vol. 16, no. 3, pp. 765-791, 2003.

[11] S. M. A. Kazmi, S. M. Imran, and R. E. A. Khan, Firms' Financial Constraints and Exporting Tendency in Pakistan, Pakistan social sciences Review, 2020.

[12] B. Bernanke and M. Gertler, "Financial fragility and economic performance," Quarterly Journal of Economics, vol. 105, no. 1, pp. 87-114, 1990.

[13] S. M. Leitner, "Financing constraints and firm growth in emerging Europe," South East European Journal of Economics and Business, vol. 11, no. 1, 2016. 
[14] T. Chaney, "Liquidity constrained exporters," Journal of Economic Dynamics and Control, vol. 72, pp. 141-154, 2016.

[15] R. Jessop, B. Diallo, M. Duursma, A. Mallek, J. Harms, and B. van Manen, Creating Access to Agricultural Finance Based on a Horizontal Study of Cambodia, Mali, Senegal, Tanzania, Thailand and Tunisia, AFD, A savoir, Paris, 2012.

[16] B. Li, C. Yao, F. Zheng, L. Wang, J. Dai, and Q. Xiang, "Intelligent decision support system for business forecasting using artificial intelligence," Arabian Journal for Science and Engineering, pp. 1-11, 2021.

[17] C. Zopounidis, M. Doumpos, and D. Niklis, "Financial decision support: an overview of developments and recent trends," EURO Journal on Decision Processes, vol. 6, no. 1, pp. 63-76, 2018.

[18] B. Huang, Y. Lu, and B. Sopranzetti, "Banking relationship and corporate financing constraints-_based on empirical evidence from Chinese private listed companies," Journal of Xiamen University, no. 02, pp. 70-81, 2019.

[19] J. Liu, M. Yang, and J. Guo, "Can supply chain finance alleviate the financing constraints of technology-based small and medium-sized enterprises? - based on the empirical data of small and medium-sized listed companies," Accounting Friends, no. 10, pp. 116-121, 2019.

[20] W. J. Baumol, "Entrepreneurship: productive, unproductive, and destructive," Journal of Business Venturing, vol. 11, no. 1, pp. 3-22, 1996.

[21] W. J. Baumol, "Textbook entrepreneurship: comment on Johansson," Econ Journal Watch, vol. 3, no. 1, p. 133, 2006.

[22] K. Godin, J. Clemens, and N. Veldhuis, Measuring Entrepreneurship: Conceptual Frameworks and Empiricial Indicators, Fraser Institute, Vancouver, Canada, 2008.

[23] J. Yi, J. Sun, and L. Yuan, "Research on the financing constraint level of agricultural listed companies-based on the analysis of stochastic frontier method," Enterprise Economics, vol. 34, no. 03, pp. 184-188, 2015.

[24] P. Aghion, C. Harris, P. Howitt, and J. Vickers, "Competition, imitation and growth with step-by-step innovation," The Review of Economic Studies, vol. 68, no. 3, pp. 467-492, 2001.

[25] Z. Acs, "How is entrepreneurship good for economic growth?" Innovations: Technology, Governance, Globalization, vol. 1, no. 1, pp. 97-107, 2006.

[26] M. Anyadike-Danes, M. Hart, and K. Bonner, "Who creates the jobs?" Significance, vol. 7, no. 1, pp. 5-8, 2010.

[27] Y. H. Yeh, C. E. Ko, and Y. H. Su, "Ultimate control and expropriation of minority shareholders: new evidence from Taiwan," Academia Economic Papers, vol. 31, no. 3, pp. 263-299, 2003.

[28] S. N. Kaplan and L. Zingales, "Do investment-cash flow sensitivities provide useful measures of financing constraints?" Quarterly Journal of Economics, vol. 112, no. 1, pp. 169-215, 1997. 